\title{
Fenomenología
}

\section{Gerardo Diego y los Juegos Florales en honor a San Juan de Dios en la revista "Paz y Caridad" (Granada, 1950)}

Gerardo Diego and the Floral Games in honor of San Juan de Dios in the journal "Peace and Charity" (Granada, 1950)

\section{Gerardo Diego e os Jogos Florais em honra a São João de Deus no jornal "Paz e Caridade" (Granada, 1950)}

Francisco Herrera-Rodríguez

Catedrático jubilado (Historia de la Enfermería y Fundamentos e Historia de la Fisioterapia. Facultad de Enfermería y Fisioterapia. Universidad de Cádiz)

Cómo citar este artículo en edición digital: Herrera-Rodríguez, F. (2018). Gerardo Diego y los Juegos Florales en honor a San Juan de Dios en la revista "Paz y Caridad" (Granada, 1950). Cultura de los Cuidados (Edición digital), 22(52). Recuperado de <http://dx.doi.org/10.14198/cuid.2018.52.02>

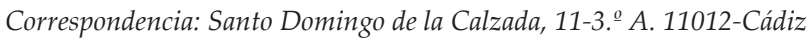

Correo electrónico: fraherod57@gmail.com

Recibido: 23/07/2018; Aceptado: 10/09/2018.

\begin{abstract}
(c) (1)
ABSTRACT

In this article we study the context in which the poem "Amor de Caridad" by Gerardo Diego was presented. The poet, born in Santander, dedicated the poem to San Juan de Dios and won, in 1950, the Floral Games which took place in Granada, on the occasion of the fourth centenary of the death of the saint. The bases, the convocation and the decision of the jury, that awarded first prize to Gerardo Diego, are exposed. Second and third prizes were won, respectively, by Manuel Benítez Carrasco and Francisco Romero López. We also offer comments about the poem and its transcription as it

was published in the magazine "Peace and Charity" (1950). In the complete works of the poet this poem appears with the title "To San Juan de Dios".

Keywords: Gerardo Diego, "Amor de Caridad", "To San Juan de Dios", Peace and Charity, Religious Poetry, Fourth Centenary of the death of Saint John of God, Floral Games, Granada, Spanish postwar period.

\section{RESUMO}

Neste artigo estudamos o contexto em que o poema "Amor à Caridade" de Gerardo Diego, dedicado a San Juan de Dios, com o qual o poeta do Santander ganhou em 1950
\end{abstract}


os Jogos Florais, realizado em Granada, por ocasião do IV centenário da morte do santo. As bases, a convocação e a decisão do Júri que premiou o primeiro prêmio a Gerardo Diego estão expostos, o segundo e o terceiro foram ganhos, respectivamente, por Manuel Benítez Carrasco e Francisco Romero López. Oferecemos comentários sobre o poema e sua transcrição como foi publicado na revista "Paz e Caridade" (1950). Nas obras completas do poeta este poema aparece com o título "A San Juan de Dios".

Palavras-chave: Gerardo Diego, "Amor à Caridade", "A São João de Deus", Paz e Caridade, Poesia Religiosa, IV Centenário da morte de São João de Deus, Jogos Florais, Granada, pós-guerra.

\section{RESUMEN}

En este artículo se estudia el contexto en que fue presentado el poema "Amor de Caridad" de Gerardo Diego, dedicado a San Juan de Dios, con el cual el poeta santanderino ganó en 1950 los Juegos Florales, celebrados en Granada, con motivo del IV centenario de la muerte del santo. Se exponen las bases, la convocatoria y el fallo del Jurado que otorgó el primer premio a Gerardo Diego; el segundo y el tercero fueron ganados, respectivamente, por Manuel Benítez Carrasco y Francisco Romero López. Ofrecemos comentarios sobre el poema y su transcripción tal y como fue publicado en la revista "Paz y Caridad" (1950). En las obras completas del poeta figura este poema con el título "A San Juan de Dios".

Palabras clave: Gerardo Diego, "Amor de Caridad", "A San Juan de Dios", Paz y Caridad, Poesía religiosa, IV Centenario de la muerte de San Juan de Dios, Juegos Florales, Granada, Posguerra española.
“... y sobre enfermos, huérfanos, tullidos, gotea zumos la granada mística".

Gerardo Diego, "Amor de Caridad".

\begin{abstract}
A la Memoria de Guillermo Montes Cala, amigo, catedrático de Griego y buen conocedor de los poetas del Veintisiete
\end{abstract}

En 1950 España aún se encontraba en una etapa de estancamiento económico general, téngase en cuenta que hasta 1954 no se consiguió la renta por individuo activo correspondiente a 1935. El periodo que abarca de 1945 a 1951 fue el periodo político más difícil, por el hambre de los años 40, por la retirada de embajadores, y por los propios efectos de la política autárquica: racionamiento, escasez de materias primas, restricciones eléctricas, etc. (Tamames, 1985). A partir de 1939 se desarrolló un amplio mercado negro que afectó a todo tipo de materias primas y productos básicos, esta circunstancia incluía a los alimentos y "perduró mientras se mantuvo el régimen de racionamiento y el sistema de intervención en la agricultura, cuyo principal instrumento fue la requisa de productos a los campesinos a precios de tasa" (Barciela, 2000). En la primera década del franquismo la industria española padeció una profunda depresión y no fue hasta 1950 que no se recuperó el nivel de producción industrial alcanzado en 1930 (Santos Juliá, 2008; García Delgado, 2000).

En estos años se potenció la empresa de recatolización de España emprendida por la Iglesia; en este sentido hay que tener en cuenta que en el ámbito educativo el control de la Iglesia fue total, además de que las autoridades educativas abandonaron la actuación en el sector público y dedicaron sus esfuerzos a sostener el sector privado, de manera que la construcción de centros de 
enseñanza fue nula: "119 institutos había en 1940 y 119 seguían en 1956: todo el incremento de alumnado se dirigió a los centros regentados por religiosos, que conocieron entonces una verdadera edad de oro..." (Santos Juliá, 2008). A todo esto hay que sumar la interpretación de la Historia de España realizada en los manuales del primer bachillerato franquista (1938-1953), revisados y aprobados por el Ministerio de Educación Nacional (Valls, 2000). El Ministro de Educación, entre 1939 y 1951, era José Ibáñez Martín (1896-1969), y su política educativa tuvo como objetivos la depuración de personas e ideas, la inculcación religiosa y patriótica, y el apoyo incondicional a la incorporación de la Iglesia y Falange a las tareas educativas (Hidalgo, 2015; Lacruz Alcocer, 1997).

La vida intelectual, una vez terminada la Guerra Civil, sufrió el silenciamiento o ausencia de sus mejores valores, además de la dura represión de las disidencias; aunque, como es sabido, la "literatura de la victoria" fue flor de un día con las obras de José María Pemán, Agustín de Foxá o Rafael García Serrano, entre otros. Tuvo más alcance la fundación de la revista Escorial (1940-1950) fundada por Pedro Laín Entralgo y Dionisio Ridruejo. Cuando esta revista publicó su último número, en 1950, la actualidad literaria era una "literatura de posguerra", mucho menos triunfalista, "en la que se mezclaban los fascistas decepcionados, los católicos con inquietudes, los liberales cautelosos y más de un oportunista" (Mainer, 2014). No se debe olvidar que en el año 1944 aparecieron la revista Espadaña y publicaciones poéticas muy importantes de Dámaso Alonso y Vicente Aleixandre, y que en 1946 aparece la revista Ínsula y al año siguiente publican obras Gabriel Celaya, José Hierro y José Luis Hidalgo, y a principios de la década de los cincuenta aparecen dos libros importantes de Blas de
Otero: "Ángel fieramente humano" y "Redoble de conciencia" (Blanco Aguinaga y otros, 1984). Y el gaditano Carlos Edmundo de Ory fundador, con otros, del postismo: "insólita reaparición de la vanguardia en plenos años 40" (Mainer, 2014), autor del que recientemente se ha publicado una extensa biografía (García Gil, 2018). No podemos olvidar, en los años cuarenta, la aparición en escena de Camilo José Cela, ni tampoco a los ensayistas de alta divulgación de finales de esta década: “...aunque con matices ideológicos muy dispares, Julián Marías, Luis Díez del Corral, Guillermo Díaz Plaja, Antonio Tovar, Pedro Laín Entralgo, José Antonio Maravall, José Luis López Aranguren y Enrique Tierno Galván, entre otros" (Mainer, 2014).

Se debe tener en cuenta también que en la década de los cuarenta jugó un papel importante la revista poética Garcilaso, fundada en 1943, y sobre todo que bajo "el signo de Garcilaso" se vivió una época de "diluvio" de sonetos, "se hablaba de Dios, Amor, Belleza, todo con mayúscula, todo como absoluto, todo como escapismo de una triste realidad", y resucitan los Juegos Florales (Blanco Aguinaga y otros, 1984), aspecto éste último que tiene un notable interés para contextualizar nuestro artículo, que precisamente versa sobre los Juegos Florales celebrados en honor a San Juan de Dios en la Granada de 1950 y que ganó Gerardo Diego con un poema titulado "Amor de Caridad", y que posteriormente titularía "A San Juan de Dios", como explicaremos más adelante.

Por todo ello, después de esta apretada síntesis de los aspectos políticos, sociales, económicos y literarios de la época en cuestión, establecemos como objetivo de este trabajo el siguiente: Estudiar el contexto en que fue presentado el poema "Amor de Caridad" de Gerardo Diego, dedicado a San Juan de Dios, y que fue publicado en 1950 en la revista "Paz y Caridad". Para desarrollar y 
cumplir con este objetivo estructuramos el artículo en los siguientes apartados:

1. La revista "Paz y Caridad" y el IV Centenario de la muerte de San Juan de Dios (1950).

2. Convocatoria, bases y premios de los Juegos Florales.

3. Gerardo Diego (1896-1987) y "Amor de caridad" (1950).

4. Epílogo.

5. Apéndice documental: Transcripción del poema "Amor de Caridad" de Gerardo Diego [Paz y Caridad (1950), 4, 357-360].

\section{La revista "Paz y Caridad" y el IV Centenario de la muerte de San Juan de Dios (1950)}

La vida y obra de Juan Ciudad Duarte, San Juan de Dios (figura 1), se desarrolló entre los años 1495 y 1550; nació en la localidad portuguesa de Montemôr-o-Novo y murió en Granada. Su actividad como pastor, soldado, librero, su encuentro con San Juan de Ávila (Martínez Gil, 2000), su visita al Real Monasterio de Santa María de Guadalupe (Cáceres), y sus fundaciones hospitalarias en las calles Lucena y Cuesta de Gomérez de Granada son suficientemente conocidas por haber sido narradas en libros hagiográficos $\mathrm{y}$ biográficos, lo cual nos exime de realizar una síntesis de su vida y obra (Cf. entre otras obras las siguientes: Castro, facsímil 1995; Labrador, 1947; Gómez-Moreno, 1950; D'Isard, 1967; Hünermann, 1976 y 1993; Asenjo Sedano, 1988; Bellido, 1995; García Martínez, 1995; Javierre, 1996; Cerro, 2000 (atribuido); Eseverri Chaverri, 2001; Martínez Gil, 2006; Ventosa Esquinaldo, 2012). Y sobre las vicisitudes históricas de la Orden Hospitalaria puede consultarse, por ejemplo, a Juan Ciudad Gómez (1963), a
Salvador Clavijo (1950a y 1950b) y a Fernández Gaytán (1983 y 1984).

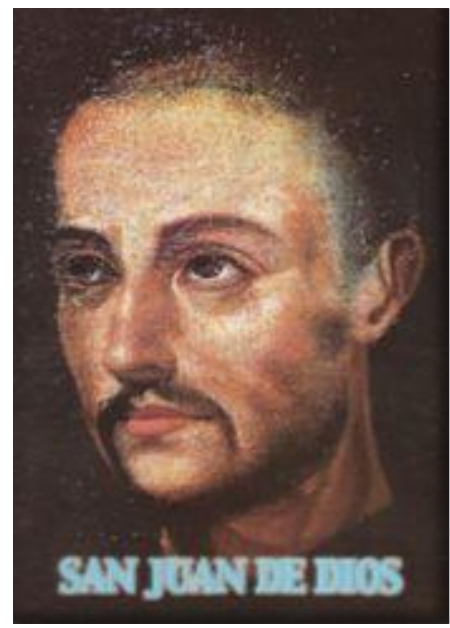

FIGURA 1: Portada del libro atribuido al Hno. Jacinto del Cerro. Aparece en esta portada el retrato de San Juan de

Dios de Pedro de Raxis (Casa de los Pisa, Granada).

La restauración de la Orden Hospitalaria en España, por Benito Menni (1841-1914), se inició en 1867 en Barcelona. Las tres Provincias españolas de la Orden han publicado revistas y boletines como, por ejemplo: "Archivo Religioso Hospitalario" (1907-1910), "Caridad y Ciencia" (1929-1934), "La Caridad" (1941-1971), "Labor Hospitalaria" (1948- ); Juan Ciudad (1980- ), etc. Debemos destacar aquí la revista de la Provincia Bética por ser la fuente principal que fundamenta nuestro trabajo: "Paz y Caridad" (1950-1980), revista que publica su primer número en el IV Centenario de la muerte de San Juan de Dios y que fue fundada por el Superior Provincial Fray Jacinto del Cerro Alcántara (López Martín, Feito Pinela, Martín Rodrigo, 2003).

Entre los actos conmemorativos del Centenario, que abarcaron desde el 8 de marzo de 1950 hasta el 8 de marzo de 1951, tuvieron lugar actividades en Granada, Madrid, Valencia, además de la visita de las reliquias a Portugal, siguiendo un itinerario 
de paso por ciudades como Granada, Sevilla, Badajoz, Montemayor y Lisboa (regreso: Lisboa, Telhal, Montemayor, Badajoz, Córdoba, Granada). Se editó también un sello conmemorativo dedicado a San Juan de Dios del cual se hizo una tirada de un millón de ejemplares. En Madrid, se programó una semana de Cirugía Ortopédica con profesionales españoles, portugueses y franceses, así como diversas actividades del gremio de libreros. Se estrenó en el Teatro Español el poema musical "Ignis flagrans Charitatis", San Juan de Dios, del compositor P. Antonio Massana, S. J., interpretado por la Orquesta Filarmónica de Madrid dirigida por el maestro Pablo Sorozábal. Además se puso en escena la comedia "Juan de Dios y Antón Martín" de Lope de Vega. En Valencia, del 31 de mayo al 5 de junio, se programó un Congreso Nacional de Psiquiatría y en Granada se programaron diversos actos, pero sólo destacaremos el que interesa en nuestro trabajo, los Juegos Florales en honor de San Juan de Dios con la participación de literatos españoles y portugueses, actuando como mantenedor el escritor gaditano José María Pemán (1897-1981) [P y C 2 (1950): 6972] (Cruset, 1964; Catálogo filatélico, 1977).

\section{Convocatoria, bases y resolución de los Juegos Florales}

En marzo de 1950, la Junta organizadora del Centenario de la muerte de San Juan de Dios convocó unos Juegos Florales, apuntando 12 temas sobre los que se podía presentar trabajos originales e inéditos en lengua castellana (tabla 1). Los trabajos debían enviarse en un sobre con un "lema" a Antonio Gallego Burín (1895-1961), Alcalde de Granada y Presidente del Comité Ejecutivo del Centenario. El plazo de admisión de trabajos tenía como fecha límite el 1 de mayo de 1950 y el fallo del Jurado debía hacerse público con antelación a la celebración de los Juegos Florales que tendrían lugar en el mes de junio del referido año. Un aspecto que se resalta en las bases del concurso es que los trabajos premiados quedarían en propiedad de la Orden Hospitalaria, que se reserva el derecho de la publicación, y en caso de llevarse a cabo el autor dispondría de 25 ejemplares sin retribución. En lo que se refiere al premio que nos interesa para el desarrollo de este artículo, el tema 1, consistía en presentar una poesía con libertad de metro y extensión alusiva a San Juan de Dios, consistiendo el premio en la "Flor Natural" y 5.000 pesetas, aunque para ese mismo tema se dotó un accésit de 1.000 pesetas, para los 11 temas restantes que se exponen en la tabla 1 la dotación del premio era de 3.000 pesetas para cada uno [P y C 2 (1950): 70-72].

El jurado calificador de los trabajos presentados al certamen literario, con motivo de los citados Juegos Florales, dejó desiertos los temas números 2, 3, 4, 5, 6, 11 y 12 (Cf. tabla 1). El tema 7 fue ganado por el Dr. J. Álvarez Sierra; los temas 8 y 9 fueron ganados por el Teniente Coronel médico de la Armada Salvador Clavijo; el tema 10 lo obtuvo el Dr. Don Rodrigo González Pinto, médico director del Sanatorio de Santa Águeda de Guipúzcoa. Y finalmente, el tema 1 que es el que nos interesa destacar en nuestro trabajo, lo ganó el poeta santanderino Gerardo Diego Cendoya que presentó, con el lema "Dos balcones", el poema "Amor de Caridad" (Cf. Apéndice documental), consiguiendo por tanto la Flor Natural y las 5.000 pesetas del Premio. El Jurado concedió en esta modalidad dos accésit, desconocemos como repartirían la cuantía económica de este Premio: el primero a Manuel Benítez Carrasco por su poema "Oración por las cosas pequeñas" y el 
segundo a Francisco Romero López, canónigo magistral de la catedral de Zamora, por el poema "El hermano de todos" [P y C, 4 (1950): 356-357] (Cruset, 1964). El poema de Gerardo Diego, motivo de nuestros comentarios, llama la atención porque reiteradamente en las crónicas de la revista se da como título "Amor de Caridad", en cambio en la propia revista cuando se reproduce íntegramente el poema lleva por título "Amor y Caridad", circunstancia que puede deberse a una errata de imprenta [P y C, 4 (1950): 357-360] (Cf. Apéndice documental). Sobre este particular volveremos más adelante cuando hagamos referencia al cambio de título del poema.

\section{TABLA 1: Temas convocados para los premios de los Juegos Florales de Granada (1950), con motivo del IV Centenario de la muerte de San Juan de Dios}

1. "Flor natural". Poesía con libertad de metro y extensión, alusiva a San Juan de Dios.

2. San Juan de Dios en la Literatura.

3. San Juan de Dios en el Arte.

4. Figuras de la época que se relacionaron con San Juan de Dios.

5. Guía de los lugares evocadores de San Juan de Dios.

6. La vida religiosa en Granada y en España en la época de San Juan de Dios.

7. La influencia de San Juan de Dios y de su Orden en el progreso de la Medicina y de la Cirugía.

8. Breve historia del desarrollo y actividades de la Orden Hospitalaria, particularmente en relación con la Armada y Ejército de Tierra.

9. La obra de la Orden Hospitalaria de San Juan de Dios en América y Filipinas.

10. La obra hospitalaria en la asistencia a los enfermos mentales.

11. La obra hospitalaria en la asistencia a los niños.

12. Breve historia y descripción del Templo y Hospital de San Juan de Dios en Granada.

FuENTE: Paz y Caridad, Número 2, marzo-abril, 1950, pp. 70-72.

La revista "Paz y Caridad" y el periódico "Ideal" de Granada (edición del día 13 de junio de 1950), ofrecieron noticias sobre el evento de los Juegos Florales, celebrados en el Palacio de Carlos V, que contó con la asistencia del Ministro de Educación Nacional, José Ibáñez Martín, al que hemos hecho alusión anteriormente, además de autoridades civiles y militares. Asimismo el acto contó con la presencia de Gerardo Diego, galardonado, que realizó la lectura de su poema, así como la del poeta granadino Manuel Benítez Carrasco, galardonado con un accésit y que realizó la lectura de su poema y del poema del otro galardonado, Romero López, canónigo de Zamora, que no pudo asistir al acto. Actuó como mantenedor de los Juegos Florales el escritor gaditano José María Pemán y Pemartín (1897-1981), que realizó un encendido discurso definiendo a los Juegos Florales como "creación provenzal y levantina", citó a Lope de Vega, calificó a España de "reserva moral" y por eso "en ella, como en un islote de luz en el mundo, pueden celebrarse estos Juegos Florales especialísimos, donde toda la belleza no es más que un reflejo de la verdad y del bien". Apeló a que sin la Contrarreforma no se comprenden los Autos Sacramentales, "que son populares en la misma medida que nacen de una raíz polémica". Sin la Contrarreforma, según Pemán, "no se comprendería nuestra teología ni nuestra mística (...) tampoco se comprendería la santidad de San 
Juan de Dios" [P y C 4 (1950): 350-355] (Cruset, 1964). Como es sabido Pemán gozó de fama de gran orador, siendo su figura y su trayectoria política complejas, ya que evolucionó desde la extrema derecha a postulados democráticos y monárquicos, circunstancias en las que no podemos extendernos en las páginas de este artículo (Álvarez Chillida, 1996; Tusell y Álvarez Chillida, 1998).

\section{Gerardo Diego (1896-1987) y "Amor de caridad" (1950).}

Como bien señala Bernal Salgado, Gerardo Diego es una de las voces centrales de la poesía española contemporánea y uno de los protagonistas más destacados del Veintisiete, se llame como se llame: Generación o Grupo Poético (Bernal Salgado, 2011; Gaos, 1975). La figura de Gerardo Diego es clave para entender la vanguardia histórica (1918-1922) y fue una de las figuras más importantes en las celebraciones del centenario de Góngora "y uno de los principales artífices de la construcción del propio Veintisiete, con diversas intervenciones claves entre las que destaca su famosa Antología Poesía española de 1932" (Bernal Salgado, 2011; Cf. también a Diego, 2007; Gallego Morell, 2008; Teruel, 2007; Gaos, 1975) (figura 2).

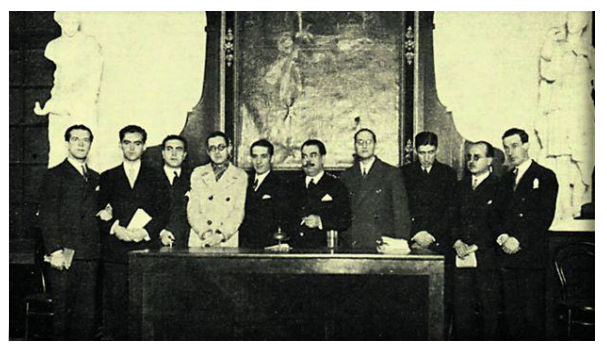

FIGURA 2: Célebre fotografía realizada en Sevilla, en 1927, atribuida a Pepín Bello. Gerardo Diego es el primero (derecha). De izquierda a derecha: Alberti, Lorca, Chabás, Bacarisse, Platero, Garzón, Guillén, Bergamín, Dámaso Alonso (FuENTE: Rondón, 2016)
A Gerardo Diego quizás le ocurre como a Rafael Alberti, que al ser autores prolíficos y diversos se les elogia o se les vitupera una $u$ otra parte de sus obras, así puede suceder con cierta poesía de circunstancia de Gerardo Diego dedicada a cuestiones jocosas o taurinas, por ejemplo, o con el Alberti de marcado compromiso político en su obra poética, que algunos señalan de tono menor. Luego está la vida y obra de los intelectuales, en este caso de los poetas, que vivieron la Guerra Civil, un trágico suceso que lógicamente no puede dejar a nadie indemne, $y$ por una $\mathrm{u}$ otra circunstancia se les saca los colores con reproches o acusaciones; en este sentido no hay más que recordar a uno de los grandes de la lírica española de todos los tiempos, Antonio Machado, al que se le recrimina a veces su admiración por la Unión Soviética o a su hermano Manuel con su poema "La sonrisa de Franco resplandece". O a Miguel Hernández y el propio Alberti con sus poemas a Stalin. En esta línea a Gerardo Diego se le recuerda como uno de los que constituyeron el "canon poético falangista", al estar incluido en el libro "Corona de sonetos en honor de José Antonio Primo de Rivera", junto a autores como Tovar, Agustí, Cunqueiro, Díez Crespo, Laín Entralgo, Manuel Machado, Marquina, Montes, Eugenio d'Ors, Pemán, Panero, Rosales, Ridruejo, Vivanco, etc. (Trapiello, 2010). Es sabido que durante la Guerra Civil Juan Larrea trató que su amigo Gerardo Diego se decantara por el "platillo republicano", y que finalmente una vez tomadas Santander y Oviedo se incorporó a la zona nacional, escribiendo poemas al general Aranda, al Alcázar de Toledo, a la División Azul y uno titulado "Hallazgo del aire", dedicado a la Legión Condor por el bombardeo de Guernica, "poema que en revisiones futuras iría transformando hasta dejarlo irreconocible" 
(Trapiello, 2010). Algunos autores no dudan en adscribirlo a la corriente garcilasista aludiendo a alguno de sus libros de carácter religioso como, por ejemplo, "Ángeles de Compostela" (Blanco Aguinaga y otros, 1984).

Además hay que tener en cuenta que durante la década de los cuarenta y cincuenta, Gerardo Diego fue un escritor laureado; por ejemplo, en 1947, fue elegido Miembro de Número de la Real Academia Española de la Lengua, ingresando en la institución al año siguiente con un discurso sobre su admirado Lope de Vega (Gallego Morell, 2008). En 1950 ganó Juegos Florales en Barcelona, Granada y Salamanca, y ofreció conferencias en Córdoba, Sevilla, Tetuán y Tánger. En 1952 recibió el premio Ciudad de Barcelona por "Amor Solo" y ganó los Juegos Florales Iberoamericanos de la Coruña. En 1955 consiguió el Premio Larragoiti y en 1956 recibió el Premio Nacional de Literatura, que ya había ganado en 1925. Como vemos en los años cincuenta se prodigó por la geografía nacional participando en Juegos Florales y ofreciendo pregones y conferencias. En la provincia de Cádiz, quizás por su vinculación con José María Pemán, dio conferencias en Jerez (1954) y Cádiz (1952), y en 1957 ganó en esta ciudad una Flor Natural, además de ofrecer conferencias en Sevilla, Málaga y Jerez. En 1959 dio conferencias y recitales en Madrid, Bilbao, Santander, Sevilla y en la capital gaditana, además de obtener el Premio Ciudad de Sevilla (Díez de Revenga, 1996; Arizmendi, 1986; Ramos Santana, 1999). Quizás todo lo apuntado sitúa a Diego como un ejemplo de poeta "oficial", reconocido y premiado en la España de Franco, mientras que otros como el poeta León Felipe o el gaditano Rafael Alberti se encontraban en el exilio, por citar tan solo dos ejemplos. Pero prosigamos indagando en otros aspectos que nos permitan comprender un poco más la obra poética dieguina.

Bernal Salgado, con acierto, ha señalado que la obra de Gerardo Diego es una de las más densas del Veintisiete, pero "es también una de las más heterogéneas y desiguales, paradójicamente comparable a la de Rafael Alberti, tan opuesto (y tan amigo) en su biografía. Así, junto a cimas líricas merecedoras de los más altos elogios, encontramos versos de circunstancia, escrupulosamente perfectos, pero sin la elevación y misterio de aquellos. Versos que, sin embargo, no son fallidos ni merecieron el repudio del poeta, sino antes bien son el fruto de su «fe poética», que desde el principio se manifestó en lo que llamamos una gozosa "polimusía", es decir: fidelidad a todas las musas, que eran nueve, y sus múltiples inspiraciones (...). Ello explica la clásica división de su obra nunca maniquea, sino profundamente trabadaen «poesía de expresión», relativa o más circunstancial; "poesía de creación", básicamente creacionista, de vanguardia o elevación" (Bernal Salgado, 2011). Otros autores cuando se refieren a la obra de Diego la califican de "arte plural" (Marín Ureña, s. f. e.).

Por eso quizás ante esta "polimusía" de Gerardo Diego, Francisco Umbral que lo trató años más tarde en el madrileño Café Gijón, señalaba su abundancia de versos ("versos para los conversos y para los reversos"), decantándose por la poesía más vanguardista del autor cántabro: "Para mí estaba vigente el Gerardo del surrealismo, el vanguardismo, el creacionismo, el ultraísmo, el gerardismo. Toda aquella poesía fresca, sorprendente, deshilada, que tenía un poco del sol parisino y cosmopolita de Apollinaire y un poco del sol madrileño y pequeñoburgués de Ramón Gómez de la Serna" (Umbral, 1978). Umbral, con mala uva, apuntó que Diego mandaba a los concursos la plica con sobre transparente, "de modo que los jurados leían «Gerardo Diego» y le daban el premio, todos los 
premios". Aunque también subrayó su bondad: "Era un hombre bueno, un corazón tímido, un poeta puro, un amigo con reservas" (Umbral, 1994).

Gerardo Diego dijo de su obra lo siguiente: "Creo que han influido en mis gustos y en mis versos algunos clásicos, Lope sobre todo, a quien adoro, y entre mis contemporáneos, el chileno Vicente Huidobro y Juan Larrea, a quien me une una entrañable amistad desde los años de Bilbao. También han influido en mi formación poética mis aficiones a la Naturaleza, a la Pintura y, sobre todo, a la Música" (Teruel, 2007). No olvidemos en este sentido que de la devoción de Diego por la música proviene buena parte de la musicalidad en sus poemas. Musicalidad y humor en una parte de su obra que supo ver Pemán: "Gerardo posee como una "turmis» de oro y magia en la que echa por una punta lo que sea -paisaje, amigo, idea-y sale por la otra la más sabrosa poesía de humor cordial que nunca se haya escrito (...). Nadie ha metido más cantidad de cosas vivas en una poesía absoluta donde todo se vuelve estética". También José Hierro, paisano de Diego, subrayó la musicalidad de sus versos, la variedad rítmica que lo emparenta con los grandes líricos del Siglo de Oro, sobre todo con Lope de Vega, y también la "irregularidad" de su obra, pero "siempre de un nivel que, en los momentos más bajos, supera al de la mayoría de los poetas". Por eso considera que este Gerardo diverso y contradictorio es, entre los poetas del Veintisiete, el más osado vanguardista y, paralelamente, el más estricto devoto de lo tradicional (Hierro, 1988). "Polimusía", tauromaquia, amor a la música (Falla, Debussy, Chopin), músico, humorista en sus "Jinojepas" y en poemas como " $\mathrm{La}$ Parlapoco". Creacionismo y poesía de expresión, y de circunstancias, en la extensa obra de Gerardo Diego, así como "Versos divinos" y una amplia obra de carácter religioso, que se entiende biográficamente por la influencia y religiosidad inculcada por sus padres, y que luego proseguiría en permanente contacto con sus hermanos sacerdotes (Rubio Martín, 2014).

Díez de Revenga, uno de sus más aquilatados estudiosos, ha señalado la importancia de la pureza y de la libertad en la obra de Diego, así como el alto valor de su faceta vanguardista, incluyendo dentro de su "poesía relativa" o "poesía de expresión", "...toda la poesía religiosa en el apartado del amor" (Díez de Revenga, 1996). Teodoro Rubio Martín, en su magistral ensayo, señala que la obra religiosa de Gerardo Diego se compone de cuatro poemarios esenciales ("Vía crucis", "Ángeles de Compostela", "El cerezo y la palmera" y "Versos divinos"), además de un libro marcado por el tema transcendente, "Cementerio civil", "...aunque numerosos poemas con esta temática hay también insertos en el resto de su obra, así como más de un centenar de artículos". Observamos que el poeta santanderino en su vertiente de ensayista, en este caso sobre la obra de Rubén Darío, subrayaba su devoción por la fe frente a las preguntas que dejaba sin responder la Ciencia, merece la pena leer el párrafo (Diego, 1967):

"La ciencia actual ha penetrado con tanta osadía y reverencia en el seno de la materia que nos quedamos ya perplejos y sin saber a qué atenernos respecto a la escolástica distinción frente al espíritu. Pero lo que la ciencia no puede darnos porque no podrá pasar de cierto umbral que le es vedado pisar, la fe nos lo entrega, la fe y el amor y la esperanza sobrevolando el término sin preocuparse de transgredir umbrales ni dinteles. Todo es uno y la fusión que vamos a ver realizarse en el seno de la poesía se ha realizado ya antes en el de la vida misma".

Efectivamente, según ha indicado Rubio Martín, Gerardo Diego es el poeta del 
Veintisiete que escribe una poesía religiosa de sentido católico y de temática concreta, dentro de la liturgia y de los dogmas de la religión romana, por eso Ernestina de Champourcin lo presenta como "el católico poeta", que no "poeta católico" (Otero, 2016). Gerardo Diego decía que "si la religión religa, la poesía también debe ligar y religar, unir a los hombres prepararlos por intermedio de su fe a la más alta fe en Dios" (Otero, 2016).

Pero centremos ya nuestros comentarios en el poema que motiva este artículo, "Amor de Caridad", y lo primero de todo algunas precisiones sobre el título y su publicación. Como ya hemos comentado con este poema Gerardo Diego ganó la Flor Natural en los Juegos Florales de Granada, celebrado con motivo del IV Centenario de la muerte de San Juan de Dios (1950). En la revista "Paz y Caridad" (figura 3), aparece titulado el poema cuando se reproduce íntegro como "Amor y Caridad", quizás por una errata de imprenta, ya que en la resolución del Jurado en la propia revista se cita como "Amor de Caridad" (Cf. Apéndice documental). En 1952, como volumen primero de la colección "Mirto y Laurel", publicó Gerardo Diego "Dos poemas (Versos Divinos)", incluyendo "A la Asunción de la Virgen María" y también "Amor de Caridad", dedicado a San Juan de Dios (Gallego Morell, 2008). Este autor en su biografía del poeta, editada en 1956 y reeditada facsímil en 2008, escribe: “...en el Palacio de Carlos V de la Alhambra de Granada recitará su composición «A San Juan de Dios»» (sic), premiada en los Juegos celebrados con motivo del centenario del Padre de los Pobres" (Gallego Morell, 2008). Quizás Gallego Morell, antes de publicar su biografía a mediados de los cincuenta, tuvo conocimiento personalmente de este cambio en el título del poema directamente por Gerardo Diego. En sus Obras completas (1989 y 1996), en las que obviamente se incluye el libro "Versos divinos" (1971), el poema se titula "A San Juan de Dios". Como vemos, el poeta cántabro se decantó por encabezar el poema con el nombre del santo, sobre el particular tan solo especulamos aquí con unos breves apuntes de cuando se pudo fraguar ese cambio. Aunque también debemos apuntar que José Cruset (1964), en su biografía "San Juan de Dios. Una aventura iluminada", transcribe el poema íntegro pero con el título "Amor de Caridad".

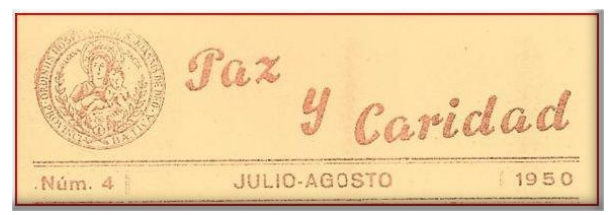

FIGURA 3: Cabecera de la revista "Paz y Caridad", número 4 del año 1950. En este número aparece publicado el poema de Gerardo Diego con el título "Amor y Caridad" (FuENTE: Biblioteca Nacional de España)

En sus Obras Completas, dentro de "Versos divinos", vemos una sección titulada "Santos"; además del poema dedicado a San Juan de Dios, encontramos tres poemas más dedicados, respectivamente, a San Sebastián, a Santa Teresa de Jesús y a San Juan de la Cruz, estos dos últimos elogiados por Díez de Revenga. Esto nos lleva precisamente al asunto, que ha sido debatido por la crítica literaria, si San Juan de Dios fue un místico contemplativo o un místico de acción. Creemos, que Rubio Martín, ha centrado bien el tema cuando afirma que:

"San Juan de Dios no es un hombre con esas experiencias místicas en las que se produce el éxtasis, sino que su mística consiste en realizar con perfección la voluntad de Dios. Mientras que el místico contemplativo se pierde en Dios, alejándose de la realidad, para identificarse con la voluntad divina, el místico de la acción, como es el caso de San Juan de Dios, se consume por Dios, cumpliendo su voluntad en la transformación de la realidad, caminando con los pobres y trabajando en las tareas terrestres de lucha contra la miseria de los desheredados". 
Quizás en determinados momentos de su vida, Juan Ciudad Duarte, pudo tener experiencias de éxtasis; pero si analizamos el conjunto de su obra asistencial, su lucha diaria y práctica para obtener medios económicos que le permitiera ofrecer a los pobres y enfermos una cama para cada uno de ellos ("jergón de paja"), ropas y alimentos, y todo ello en un lugar limpio y caldeado, vemos que su acción tiene como raíz las obras de misericordia, la caridad que es amor en acción, por eso pensamos que Gerardo Diego acertó con el título del poema cuando lo presentó al concurso, "Amor de Caridad", aunque pueda parecer redundante la utilización conjunta de las dos palabras enlazadas con una preposición. Rubio Martín destaca varios versos de este poema, pero uno en concreto que viene a corroborar esta idea: "...es Caridad, amor de solo espíritu". Y por eso Gerardo Diego llama a Juan Ciudad Duarte, "Juan de Dios y del Prójimo". Con estos versos cierra el poema:
"Saber la Caridad es la suprema, rica sabiduría.
De esa ciencia de amor ya deletrean
Hijas, hermanos legos la cartilla y sobre enfermos, huérfanos, tullidos, gotea zumos la granada mística".

"Gotea zumos la granada mística", o sea la caridad, el amor en acción, la solidaridad de cuerpo y espíritu con el ser humano pobre, enfermo y doliente. Esto no fue una tarea fácil, en cualquiera de las biografías citadas se pueden leer las dificultades diarias que tuvo San Juan de Dios para encontrar recursos efectivos y que goteara zumos la granada mística porque "tanto las deudas como los pobres aumentan sin cesar". A la Duquesa de Sesa le escribió lo siguiente en una de sus cartas: "...el día que tengo que pagar a los trabajadores se quedan algunos pobres sin comer". Y como dice Juan Félix Bellido cada pobre, cada enfermo, no es un número anónimo, es un prójimo al que amar, y a aquel que quería incorporarse a trabajar en el hospital, como en el caso de Luis Bautista, Juan Ciudad no dudaba en decirle: "Si os decidís a venir aquí, será necesario que estéis dispuesto a hacer algo por Dios y a dejar el cuero y las correas"; es decir, debía "dejarse la piel" (Cartas; Bellido, 1995).

Juan de Dios, ¿un místico? Quizás, pero en todo caso un místico de acción como ha sabido ver con precisión el gran estudioso, Rubio Martín, de la obra religiosa de Gerardo Diego. Juan Ciudad no se aleja de la realidad y de su realidad cotidiana, que a partir de un determinado momento fue la de paliar la pobreza y ayudar al enfermo en una Granada en la que por supuesto hacían mucha falta los libros, pero sobre todo hacía falta el pan, la cama caliente y el consuelo a todos aquellos dolientes que transitaban por sus calles en las primeras décadas del siglo XVI ("¿Cómo es la Caridad? Nadie lo sabe. / Para saberlo es menester ser víctima,..."). La caridad puede ser una mística; pero en el caso de Juan Ciudad Duarte, una mística de acción inseparable del prójimo, inseparable de la "víctima". La caridad "esa ciencia de amor". Por eso este hombre caminaba por las calles de Granada repitiendo incansablemente una letanía: "Hermanos, haced el bien a vosotros mismos dando limosna a los pobres". O en sus Cartas podemos leer: "Tened siempre caridad, que donde no hay caridad no hay Dios, aunque Dios en todo lugar está". Con seguridad Gerardo Diego al escribir el poema que analizamos tuvo muy presente el magisterio de la Iglesia y su doctrina social, recuérdense los escritos de León XIII o la "caridad social" expresada por Pío XI en su encíclica Quadragesimo Anno (1931), en la que se refiere al amor social como el alma de un orden justo (Cruz Ayuso, 2016). Encíclica que seguramente conocía el poeta santanderino. Además fue Pio XI, en 1930, el Pontífice que lo 
proclamó "Patrón de los Enfermeros de ambos sexos" (Cruset, 1964).

\section{TABLA 2: Cambios gramaticales, de puntuación y de versificación encontrados en "Amor de Caridad" ("Amor y Caridad") y en "A San Juan de Dios"}

\begin{tabular}{|c|c|c|}
\hline $\begin{array}{l}\text { Números de } \\
\text { los versos } \\
\text { modificados }\end{array}$ & $\begin{array}{l}\text { “Amor de Caridad” o “Amor y Caridad” } \\
\text { de Gerardo Diego } \\
96 \text { versos } \\
\text { (Revista “Paz y Caridad": 1950, Número 4, pp. 357-360) }\end{array}$ & $\begin{array}{l}\text { “A San Juan de Dios" de Gerardo } \\
\text { Diego } \\
97 \text { versos } \\
\text { Obras Completas (1989), tomo II, pp. } 642-645\end{array}$ \\
\hline 8 & -rebullicio de pájaros- & -rebullicio de pájaro- \\
\hline 13 & más allá de los siglos sus saetas & más allá de los signos sus saetas \\
\hline 16 & en otro sol de octubre antiguo y raro, & el otro sol de octubre antiguo y raro \\
\hline 17 & y besándose fiel la frente nueva, & y, besándole fiel la frente nueva, \\
\hline 20 & Y el ayer y el mañana entresoñados & El ayer y el mañana entresoñados \\
\hline 21 & están aquí en un puro, inmóvil éxtasis, & están aquí, en un puro, inmóvil éxtasis, \\
\hline 24 & -botón florido, aun por abril, sellado- & -botón florido, aun por abril, sellado-, \\
\hline 29 & y lo retiene aquí en la jaula abierta, & y le retiene aquí, en la jaula abierta, \\
\hline 36 & cuatro por una es cuatro, & $« 4$ por 1 es 4. \\
\hline 37 & cuatro por dos son ocho, & 4 por 2 son 8 . \\
\hline 38 & cuatro por tres son doce, & 4 por 3 son 12 . \\
\hline 39 & cuatro por cuatro, dieciséis. & 4 por $4,16 »$ \\
\hline 48 & Inmóvil, evadido de dolores & Inmóvil, evadido a los dolores, \\
\hline 49 & puede el yacente sumergirse en sueños & puede el yacente sumergirse en sueños. \\
\hline 54 & Se mira como fué, mozo, gallardo, & Se mira como fue, mozo gallardo, \\
\hline 70 & que es el Amor de Dios, y nada pide & que es el amor de Dios, y nada pide \\
\hline 72 & es Caridad, amor de solo espíritu & es Caridad, amor de solo espíritu, \\
\hline 86 & Juan de Dios y del prójimo; y ahora, & Juan de Dios y del prójimo, y ahora, \\
\hline $87-88$ & $\begin{array}{l}\text { 87: } \\
\text { granada ya su vida en la celeste acrópolis, }\end{array}$ & $\begin{array}{l}87 \text {-88: } \\
\text { granada ya su vida } \\
\text { en la celeste acrópolis, }\end{array}$ \\
\hline $89-90$ & $\begin{array}{l}\text { 89: } \\
\text { Caridad, una y trina que se entrega; }\end{array}$ & $\begin{array}{l}\text { 90: } \\
\text { Caridad trina y una que se entrega, }\end{array}$ \\
\hline 94-95 & $\begin{array}{l}\text { 94: } \\
\text { Hijas, hermanos legos la cartilla }\end{array}$ & $\begin{array}{l}\text { 95: } \\
\text { Hijas, Hermanos legos la cartilla }\end{array}$ \\
\hline
\end{tabular}

En "Amor de Caridad", dedicado a San Juan de Dios, en la edición del poema de 1950, que aparece en la revista que estudiamos, contabilizamos 96 versos (Cf. apéndice documental), y se cuentan 97 en "A San Juan de Dios" en las Obras Completas; encontramos también algunas variantes gramaticales en las dos versiones del poema, cambios que especificamos en la tabla 2 .
También debemos apuntar que Cruset (1964) transcribió este poema en su biografía de San Juan de Dios, contabilizándose en esta transcripción 97 versos, incluso observamos que en la transcripción de este autor están algunos de los cambios en el poema que aparecen en las Obras Completas de Gerardo Diego, pero también conserva detalles gramaticales del poema iguales a 
como apareció en 1950 en la publicación de la revista "Paz y Caridad". Hay que tener en cuenta también que José Cruset califica a Gerardo Diego como "mi querido amigo" (Cruset, 1964), pero desconocemos si esta versión transcrita en su libro fue revisada o no por el poeta cántabro, en la misma no están los espacios entre las estrofas tal y como aparecen en las Obras Completas, ni tampoco como aparecen en "Paz y Caridad" en 1950.

Se ha apuntado que este poema es una silva, recuérdese que en el arte de esta estrofa fueron maestros Quevedo, Góngora y Bécquer. El poema ha sido estudiado, formalmente y en cuanto a su contenido, por Teodoro Rubio Martín en su excelente libro "La obra religiosa de Gerardo Diego (Verso y prosa)". En sus páginas dice lo siguiente, recurrimos una vez más a la sabiduría de este autor:

"El poema titulado "A San Juan de Dios" tiene 97 versos. Se distinguen fácilmente cuatro partes. El poeta utiliza la silva, alterna versos endecasílabos con heptasílabos -en rima asonante los pares. La primera parte presenta la infancia de San Juan de Dios, a la que el autor identifica con el "sol de octubre" (...), su etapa escolar. La segunda, al santo en su ancianidad, a la que el autor identifica con el "sol de mayo" (...). La tercera es un canto al amor en todas sus vertientes: de pareja, maternal y divino (...), que el poeta llama "caridad" (...). En la cuarta parte, reflexiona sobre la caridad y afirma que es "la suprema rica sabiduría" (...) que aprendieron San Juan de Dios y otros muchos religiosos y religiosas, siguiendo su ejemplo, entregados a enfermos, huérfanos y tullidos".

Del sol de octubre (la infancia) al sol de mayo (ancianidad). El otoño, pues, dora la infancia del niño y la primavera alegra el alma del viejo. En la primera parte hay remembranzas escolares que, efectivamente, recuerdan el célebre poema de Antonio
Machado (Rubio Martín, 2014). Véanse estas resonancias machadianas en "Amor de Caridad":

"Está el balcón abierto al sol de octubre.

El tibio, oblicuo halago

resbala su caricia

sobre el libro escolar como una mano.

La historia universal fulge y palpita

-oros y fuegos, Nínive y Bizancio-.

Sueña el niño y la hoja

-rebullicio de pájaros-

mueve el ala cautiva

alborotando brisas y relámpagos".

Los versos son limpios, diáfanos, respiran un aire evocador y una belleza serena; en algún pasaje brota el botón florido de Darío o el de Lope, y en otros como se ha apuntado las multiplicaciones escolares de "Recuerdo infantil" de Antonio Machado. "Blancas y azules voces cantan, cantan: / cuatro por una es cuatro,...". La mística aflora en los versos de Diego cuando el anciano se contempla (espacios y tiempos se funden), se ve niño, niega la vejez y las "llagas no supuran", aunque "A abrevarse en las llagas/entran las moscas...". Este poema de Diego, alejado en la forma de su etapa vinculada al "creacionismo", tiene conexión en cambio, en el fondo, con su célebre poema "Rosa mística", en el que además del trasfondo religioso ("Anidaba en sus ojos/ el avemaría"), aparecen imágenes como “... sus manos ojivales/que daban de comer a las estrellas". En "Amor de Caridad": la caridad, amor que va de alma a alma por la línea más recta, "mueve ya otro sol y otras estrellas". De la "rosa mística" a la "granada mística". Todo un recorrido por el que nos han enseñado a transitar, entre otros, Gallego Morell, Rubio Martín, Díez de Revenga, Bernal Salgado e incluso Guillermo Díaz Plaja con su olvidado manual de Historia de la Literatura Española. 
Gerardo Diego no sólo tuvo presente en su extensísima obra de carácter religioso a Santa Teresa de Jesús y a San Juan de la Cruz, entre medio se coló un San Sebastián y un menesteroso e insistente San Juan de Dios que apelaba a las conciencias de sus contemporáneos sobre la situación de los pobres y enfermos. Debió ser su figura muy querida por Gerardo Diego porque en 1970, en la revista "Original", publicó un artículo titulado "San Juan de Dios". Asimismo, y como ha hecho notar Rubio Martín, Gerardo Diego exaltó también los principios solidarios de la caridad en un poema titulado "Caridad en la India", dedicado a las "Hijas de la Caridad que están en las misiones de la India, trabajando con huérfanos, ancianos y abandonados, incluso en lugares inhóspitos como la selva..." (Rubio Martín, 2014). Un poema que es fácil de encontrar y de leer en sus Obras Completas, y en el que escribe algunos versos en el que nos parece apreciar un trasfondo formal rubeniano, pero en otros aparece la veta mística y la exaltación de la caridad. Leamos un fragmento:

\footnotetext{
"Vosotras sois de Caridad Hermanas, vosotras sois sus Hijas.

Y vosotras también, como la Esposa

de los Cantares, la zagala mística

que en el rapto olvidada

el mosto paladea de encendidas

lámparas de granadas,

os derramáis castísimas".
}

Como hemos visto en las páginas precedentes, Gerardo Diego fue el ganador de los IV Juegos Florales celebrados en Granada, en 1950, en homenaje a San Juan de Dios. Pero este certamen literario, en la convocatoria de poesía, tuvo otros dos galardonados con accésit: el segundo premio lo obtuvo Manuel Benítez Carrasco, con su poema "Oración por las cosas pequeñas", y el tercer premio fue para
Francisco Romero López, canónigo de Zamora, por su poema "El hermano de todos". Los dos poemas fueron publicados también en la revista "Paz y Caridad", y el primero de ellos fue transcrito también por Cruset [P y C 5 (1950): pp. 109-113 y pp. 114-115] (Cruset, 1964).

Manuel Benítez Carrasco (1922-1999), nació en el Albaicín granadino. Su obra poética ha sido incardinada dentro de la lírica del neopopularismo y el folklorismo por el tono y las estrofas de corte popular, aunque también cultivó la décima y el soneto. Entre sus obras literarias: "La muerte pequeña", "El oro y el barro", "Anecdotario del agua", "Aires andaluces", etc. Benítez Carrasco tuvo vocación de recitador realizando grabaciones discográficas como "Mi poesía andaluza" (Carvajal, consultado 2018). De hecho en la velada de los Juegos Florales, celebrada en Granada en el verano de 1950, recitó el poema con el que ganó el segundo premio e incluso la revista que estudiamos publicó su fotografía en plena declamación del poema [P y C 4 (1950): p. 356]. Un poema en el que también ensalza la caridad:

"Yo bien sé, Juan de Dios, que si, en lugar de ser
muleta redentora de todas las cojeras
y corazón dolido de todas las desgracias,
fueras un jardinero
del Señor en Granada,
en mi jardín no habría
ni fuentes desvalidas ni rosas desoladas.
Porque tu Caridad tendría siempre
a punto de milagro o a bálsamo de lágrimas
una palabra buena como un responso amigo
para la rosa en ruinas, para la fuente seca,
tu voz hermana y dulce como un rumor de agua".

Manuel Benítez Carrasco, en 1996, presentó en Sevilla su libro "Aires de Andalucía", editado por la entidad filantrópica el Club de Leones; un libro 
cuyos beneficios estarían destinados a la compra de una cocina para donarla a los Hermanos de San Juan de Dios del asilo de ancianos de la calle Misericordia de Sevilla (Montoya, 1996). Curiosamente, el nombre de Benítez Carrasco aparece vinculado nuevamente a la Orden de San Juan de Dios, cuarenta y seis años después de haber obtenido el segundo premio en los Juegos Florales de Granada que venimos glosando en este artículo.

El tercer premiado, como hemos comentado, fue Francisco Romero López, conocido como el Magistral Romero. Romero nació en el Barco de Ávila, en 1887, y murió en Zamora en el año 1964. Fue canónigo magistral de la Catedral de Zamora y autor de un libro sobre leyendas y tradiciones zamoranas que fue reeditado en 2010 (Romero, 2010). El poema con el que obtuvo el tercer premio lleva por título " $E l$ hermano de todos", vertebrado en cuatro cantos: Canto I (Pastor); Canto II (Soldado); Canto III (Loco) y Canto IV (Santo). Comienza así el poema, algunos de sus versos recuerdan a la lírica de San Juan de la Cruz, pero qué difícil es mantener el tono en todos los versos, algún que otro fragmento quedaría muy bien en la voz pura de ese gran trovador que se llama Amancio Prada:

"Vaga el Pastorcico
por la quebrada Sierra toledana,
y en su blanco pellico
en perlas se desgrana
la escarcha -hielo y luz- de la mañana.
El silencio despierta
en el lecho rosado de la aurora,
da a las aves su alerta
la flor madrugadora
y el Tajo en el barranco canta y llora".

\section{Epílogo}

En el transcurso de la redacción de este trabajo ha permanecido instalada en $\mathrm{mi}$ conciencia la tensión de la belleza poética de los versos de Gerardo Diego, tanto de sus libros más puramente creacionistas como parte de su poesía religiosa, tradicional, y en buena medida entroncada con los clásicos. El propio Diego era consciente sobre, y así lo manifestó en 1931, "las dificultades con que tropieza el artista de nuestro tiempo para tratar un tema religioso son más que nunca crecidas"; sabía que después del siglo XVII no eran frecuentes las poesías religiosas "tolerables para una sensibilidad fina y despierta" (Vidal Ortuño, 2013). Esto es cierto, sin duda, pero en los años cuarenta y cincuenta este tipo de poesía creció en cantidad y poco en calidad, alentada quizás por la convocatoria de numerosos Juegos Florales a lo largo y ancho del país, como hemos tenido ocasión de comentar en este artículo. Aunque no es el caso de "Amor de Caridad", su belleza poética la hemos dejado señalada en las páginas precedentes.

Una España de cartillas de racionamientos, recuérdese que hasta 1952 no se suprimen, en que los productos básicos como el pan, el aceite, las patatas, el azúcar o el jabón tenían unos precios oficiales marcados, pero las clases menesterosas veían y padecían como esos precios se disparaban debido al estraperlo; un país en que las enfermedades como, por ejemplo, la tuberculosis se cebaban con la población (Abella, 1996; Eslava Galán, 2010; Vázquez Montalbán, 1986; Molero Mesa, 1994; HerreraRodríguez, 2005). En una España, como decimos, de hambre y miedo proliferaron los Juegos Florales y sus flores naturales. En 1950, como hemos visto, estos Juegos Florales estuvieron dedicados a un santo menesteroso y pobre que en la Granada de su época llamaba a todas las puertas, y 
voceaba por las calles, pidiendo limosnas para las personas que atendía en sus hospitales. Su época fue difícil, abundante de pobres y enfermedades; la posguerra española también fue una época extremadamente dura, y muchas personas pobres y humildes ni se enterarían de la Velada celebrada en honor al Santo en el Palacio de Carlos V, en la que actuó de maestro de ceremonias José María Pemán y fue premiado en buena lid con un gran poema Gerardo Diego, premiado además de con la Flor Natural con 5.000 pesetas, que no era poco en la época que estamos tratando. La Orden Hospitalaria, con motivo del IV Centenario de la muerte del Santo, recibió la Cruz de la Beneficencia [P y C. 5 (1950): pp. 99-108]. Pero sigamos hablando de poesía, de la buena poesía de uno de los grandes maestros del Veintisiete y también sobre algunos aspectos complementarios sobre la poesía religiosa y la figura de San Juan de Dios en la literatura y en el arte.

En 1950, precisamente, León Felipe, exiliado, amigo en su juventud de Gerardo Diego, sacó a la luz la primera edición en México de sus "Versos y blasfemias de caminante" con el título "Llamadme publicano". León Felipe se quejaba así sobre la suerte de sus poemarios, palabras elocuentes que ayudan a comprender dos momentos históricos: "Siempre he sido un hombre inoportuno y un español desentonado y anacrónico. Ayer, en 1920, cuando la blasfemia corría por las costanillas y por las grandes avenidas de Madrid como el agua de las lluvias hasta encontrar el sumidero, escribía yo mi primer libro con el nombre de «Versos y oraciones de caminante». Y en 1940, veinte años más tarde, cuando los escritores españoles, los de la «Santa Cruzada» y muchos de los del «Éxodo» también, movían sus plumas como palmas para relatar, arrepentidos y devotos, las vidas ejemplares de los santos, iba yo a dar a la estampa mis últimos poemas con el título "Versos y blasfemias de caminante». Nadie los quiso. No encontré editores. $Y$ no intenté violentar en nada la decisión del Viento, de ese Viento que es mi antólogo, mi colaborador y el dictador. El que selecciona, el que me ayuda..." (Felipe, 1981; 1984).

En ese mismo año, 1950, Blas de Otero publicó su gran poemario "Ángel fieramente humano", en el que vuelca una poesía de marcado acento existencial, que en ciertos aspectos conecta con la de Miguel de Unamuno, y en la que en el poema "Hombre" leemos lo siguiente: "Luchando, cuerpo a cuerpo, con la muerte, / al borde del abismo, estoy clamando / a Dios. Y su silencio, retumbando, / ahoga mi voz en el vacío inerte / (...) / Esto es ser hombre: horror a manos llenas. / Ser -y no sereternos, fugitivos. I ¡Ángel con grandes alas de cadenas!". Una poesía de carácter religioso muy diferenciada de la de Gerardo Diego. Recuérdese también que en 1968 Blas de Otero manifestó en una entrevista que desde 1955 no había podido publicar un libro en España, salvo alguna reedición de libros anteriores y mutilaciones en la edición española de "Que trata de España", todo ello efecto de la censura padecida por su obra (Cruz, 1981).

En 1944 se publicó el poema "Insomnio" de Dámaso Alonso, en el que también se aprecia una religiosidad dolorida, muy diferente a la de su compañero del Veintisiete, Gerardo Diego. Escribe Dámaso: "Madrid es una ciudad de más de un millón de cadáveres / (según las últimas estadísticas). I A veces a la noche yo me revuelvo y me incorporo en / este nicho en el que hace cuarenta y cinco años quelme pudro,... / ... Y paso horas preguntándole a Dios, preguntándole porlqué se pudre lentamente mi alma, / por qué se pudren más de un millón de cadáveres en/esta ciudad de Madrid, I por qué mil millones de cadáveres se pudren lentamente / en el mundo". Se ha dicho 
que Dámaso Alonso empalmó con la tradición mística como salvoconducto poético de todo lo que venía guardando en el tintero como impropio de un poeta impuro, pero también era una manera de ganarle la partida al "fungáceo superrealismo", "al garcilasismo, y a la ñoñería general de la poesía religiosa y/o imperial en aquellos años" (Silver, 1979). Como indica Philip W. Silver, Dámaso Alonso, adentrándose en la tradición mística vislumbra y recoge la misma problemática que tuvo a mal traer al propio Mallarmé: "esto es, tomar la medida del ser humano, ontológicamente indigente, respecto a las categorías del ser". Gerardo Diego y Dámaso Alonso, dos compañeros del Veintisiete, profesores, ¿dos maneras diferentes de abordar en sus obras la mística y la poesía religiosa? Parece evidente que sí. Lo cual es un acicate para que volvamos una y otra vez a sus obras que al día de hoy son clásicas. Si a Dámaso Alonso lo hemos entendido aquí desde lo ontológicamente indigente, como acabamos de apuntar, quizás debamos explorar buena parte de la poesía religiosa de Gerardo de Diego desde el punto de vista de la felicidad, como hizo Bengoechea en su ensayo "La felicidad en San Juan de la Cruz". No podemos, en este artículo, analizar cuál de estos dos poetas, Dámaso y Diego, tuvo más influencia (además de Unamuno, Antonio Machado, así como los demás poetas que configuraron el grupo poético del Veintisiete) en los poetas de "el grupo poético de los años 50", me refiero claro está a Ángel González, Caballero Bonald, Costafreda, Valverde, José Agustín Goytisolo, Gil de Biedma, Valente, Brines, el precoz Claudio Rodríguez, etc. (García Hortelano, 1978; García Tejera y Hernández Guerrero, 2003).

Como ha precisado el gran estudioso de la poesía religiosa de Gerardo Diego, Teodoro
Rubio Martín, "Versos divinos" tiene un gran inspirador en buena parte de los poemas que lo constituyen, y ese gran inspirador no es otro que Lope de Vega, gran sonetista, al igual que el autor de "El ciprés de Silos", poema sobre el que escribió un notable ensayo Gallego Morell (1972), autor al que debemos una impagable "Vida y poesía de Gerardo Diego", obra que fue reeditada en 2008. Es sabido que Lope de Vega publicó una comedia titulada "Juan de Dios y Antón Martín", inspirada al parecer en la biografía del sacerdote Francisco de Castro. Una comedia hagiográfica que los expertos datan entre 1611 y 1612, y cuyo eje estructural es el sacramento de la penitencia, transcurriendo la acción durante el reinado de Carlos $\mathrm{V}$ y principios del de Felipe II, en pleno movimiento contrarreformista (ChouzaCalo, 2017). Esta comedia de Lope, según ha señalado Cruset (1964), no era del gusto de Menéndez Pelayo, incluso el propio Cruset señala que en lo que se refiere a los aspectos biográficos "no conduce sino a confusión".

San Juan de Dios, pues, un motivo más para vincular a Lope de Vega y a Gerardo Diego, aunque teniendo en cuenta los motivos temáticos de ambos (Lope, la penitencia; Diego, la caridad), y sin pretender claro está establecer comparaciones entre la España de la Contrarreforma y la España de la posguerra. No se debe olvidar que Lope de Vega dedicó también al santo un poema, en el que ensalzó la caridad, titulado "Canción al escelso Padre y Patriarca San Juan de Dios". También lo hizo, en el siglo XVII, Francisco Trillo y Figueroa con su poema "Al Santo Juan de Dios quando predicando a las mujeres de la casa pública les dio dineros por que le oyessen y convirtió algunas". Incluso Calderón de la Barca profesó devoción por San Juan de Dios, dedicándole en 1690, una colección de autos sacramentales (Cruset, 1964). 
Como es sabido Gerardo Diego ganó el Premio Cervantes de literatura en 1979, compartió premio con el escritor argentino Jorge Luis Borges; curiosamente, este Premio también lo obtuvo, en su caso en el año 1991, el escritor granadino Francisco Ayala. Además de tener entre sus galardones este gran premio de las letras españolas, Diego y Ayala comparten también el aprecio por la vida y obra de Juan Ciudad Duarte, San Juan de Dios. Ya hemos visto y comentado el poema "Amor de Caridad"; en el caso de Francisco Ayala encontramos dentro de su narrativa una obra de algo más de veinte páginas, incluida dentro de su libro "Los usurpadores", publicado en 1949, que lleva por título "San Juan de Dios", obra que también encontramos editada conjuntamente con otra narración titulada "El hechizado" (Ayala, 1993; 2002). Carolyn Richmond ha señalado que este librito sobre San Juan de Dios es una de las narraciones más conmovedoras de las incluidas en "Los usurpadores", y que está inspirada en un antiguo cuadro de la familia de Ayala, "que sirve como punto de partida real para un relato imaginario sobre la vida de este santo venerado en su ciudad natal, cuenta el autor una historia de trágica rivalidad y de posterior salvación espiritual por virtud de la «caridad ardiente», vivida por dos caballeros granadinos". El cuadro colgado en una pared de la casa de su infancia, según cuenta el propio Ayala en "Recuerdos y olvidos", representa a San Juan de Dios en la hora de su muerte. Precisamente en este excelente libro de memorias nos ofrece Ayala alguna clave más sobre esta obra dedicada al santo mendigo, que también encontramos reproducida en el estudio de Richmond. Leamos (Ayala, 1982; Rychmond, 2002):

"Mi madre sentía particular veneración hacia ese santo fundador de una comunidad hospitalaria en Granada; veneración que era un eco ampliado del respeto tenido por mi abuelo ella me lo explicó más de una vez-hacia esos hermanos de San Juan de Dios que tan caritativamente asistían a los desvalidos enfermos. Aunque él no era creyente, admiraba la abnegación cristiana de esos hombres, tanto como la de unas monjas, las Hermanitas de los Pobres, a quienes igualmente favorecía y a cuyos asilados prestaba, por supuesto, su asistencia médica gratuita. A ambas organizaciones católicas contribuía también mi madre con su óbolo, aún en los momentos de nuestra mayor penuria. Ponderaba la alegría piadosa con que esas humildes mujeres servían a los ancianos recluidos en su asilo, teniéndolos limpios como una patena y bregando con sus chocheces, idiosincrasias e irascibilidades sin perder nunca el humor".

Este relato de Francisco Ayala parece tener un trasfondo proustiano, en la medida en que un cuadro en el que figura representado San Juan de Dios, de su casa natal, de su infancia, muchos años después el recuerdo le llevará a escribirlo y quedará incluido en un libro imprescindible dentro de la obra del escritor granadino: "Los usurpadores". Llama la atención que estos dos Premios Cervantes (uno se quedó a vivir en la España de Franco $y$ fue un poeta laureado en los años cincuenta, Gerardo Diego, y el otro, Francisco Ayala, vivió durante décadas en el exilio) coincidieran en sus extensas e importantes obras en la figura de San Juan de Dios; el primero con su poema y un artículo, el segundo con una emotiva narración de la que hemos glosado de donde parte su inspiración.

La figura de San Juan de Dios no solo ha inspirado a poetas y narradores, también ha llamado a la puerta de cineastas, pintores y escultores. Vayamos por partes. Se cumplen ahora cuarenta años del estreno, en agosto de 1978, de la película "El hombre que supo amar", dirigida por Miguel Picazo de Dios 
(1927-2016), basada en la vida y obra de San Juan de Dios. A Miguel Picazo, después de su primera película "La tía Tula" (1964), basada en la obra de Miguel de Unamuno, calificada como la obra maestra del cineasta, se le miraba con lupa cada nueva película que estrenaba. Si nuestros cálculos no fallan ésta dedicada a San Juan de Dios es la cuarta que sacó a la luz pública, y recibió una crítica demoledora de Fernando Trueba (1978):

"Picazo, con evidente ambición, ha tratado de realizar un fresco de toda una época, con un criterio indeciso entre dos influencias antagónicas: la de Zeffirelli y la de Pasolini. El Juan Ciudad de El hombre que supo amar se asemeja en muchos momentos al Francisco de Asis de Hermano Sol, hermana Luna (...). Todo es bastante tosco. Derroche de medios no controlados, desafortunadas escenas de masas, etcétera. El enfrentamiento de Juan Ciudad con las estructuras sociales, políticas y religiosas de su tiempo es utilizado por Picazo para resumir los conflictos de una época bastante compleja. Y así, la película cae en su más grave defecto: un esquematismo de tono pseudodidáctico. Los diálogos son falsos, demagógicos, tendenciosos y efectistas. Juan Ciudad viene a ser una especie de progre adelantado a su tiempo, que ofrece una alternativa psiquiátrica a los cruentos métodos de la época".

La película de Miguel Picazo se basó en la biografía de San Juan de Dios escrita por José Cruset y el guion lo firmó Santiago Moncada. Es cierto que esta película de Picazo no está al nivel de su obra maestra, "La tía Tula"; pero dada la complejidad técnica que supone hacer una película de época, con tantos actores y temas, la consideramos digna, aunque sí se le pueden demandar aspectos cronológicos más elaborados como, por ejemplo, cuando se hace referencia a Miguel Servet y la circulación de la sangre. Miguel Picazo intentó en esta película ofrecer una visión humana de la figura de Juan Ciudad Duarte y por eso el cineasta merece nuestro respeto.

También los pintores y los escultores han dedicado sus obras a la figura de San Juan de Dios. En esta vertiente es materialmente imposible realizar la nómina de los artistas que lo han hecho, y por eso quizás una visita a la Basílica, al hospital, al Museo de Bellas Artes y a la Casa de los Pisas en Granada pueden ofrecer una muestra de lo que decimos. En este itinerario granadino se puede encontrar el primitivo retrato de San Juan de Dios de Pedro de Raxis El Viejo, el conocido cuadro de Gómez Moreno en que el santo mendigo baja las escaleras del Hospital Real de Granada, salvando la vida en un incendio a algunos de los enfermos ingresados, o también el de Sánchez Coello. Y las esculturas de Pedro de Mena, Montañés, Buiza, Alonso Cano, etc. (Ruiz Ortega, 1983; Gil Medina, 2003; Carrasco de Jaime, 2004). En Sevilla, en la Iglesia del Hospital de la Santa Caridad, el magnífico cuadro de Bartolomé Esteban Murillo en el que se representa a San Juan de Dios transportando a un enfermo. En Cádiz, en la Iglesia de San Juan de Dios, se encuentra la imagen del siglo XVII atribuida al escultor Francisco de Villegas, y en los fondos museísticos de la Hermandad de la Caridad dos óleos anónimos del siglo XVIII: "Apoteósis de San Juan de Dios" y "Aparición de la Virgen vestida de pastora a San Juan de Dios" (Alonso de la Sierra, 2017). Asimismo, en otra vertiente, encontramos biografías ilustradas como la realizada por el pintor italiano Onofrio Bramante (1926-2000), editada en Roma por la Curia Generalizia dei Fatebenefratelli. Inagotable, como decimos, el arte dedicado a la figura de San Juan de Dios, pero de todas ellas por su sencillez y humanidad apreciamos el cuadro de Pedro de Raxis (figura 1). 
Concluimos. Hasta aquí llegan nuestros comentarios sobre el poema de Gerardo Diego dedicado en 1950 a San Juan de Dios, más allá de hacer crítica literaria lo que hemos querido presentar en este trabajo es una labor de contextualización de los citados Juegos Florales y de la España de la época, enmarcando el poema dentro de la caridad sentida y vivida por este místico de acción, San Juan de Dios, recordando también la devoción de Gerardo Diego por Lope de Vega, autor de nuestro Siglo de Oro que dedicó una comedia y un poema a este hombre que consumió sus fuerzas y sus energías ayudando a pobres y enfermos en la Granada del siglo XVI.

Quizás muchas personas con pocos recursos económicos, en la Granada de 1950, conocían la vida y obra de Juan Ciudad Duarte, San Juan de Dios, por alguna lectura o por tradición oral, o incluso eran devotos del santo; pero quizás no muchas de estas personas llegaran a tener conocimiento de la Velada literaria celebrada en el Palacio de Carlos V, con discursos de autoridades y poetas, bastante tenían con lidiar el día a día paliando sus necesidades básicas y las de sus familias con las cartillas de racionamiento, $y$ luchando contra el escarnio del estraperlo.

\section{Apéndice documental: Transcripción del poema "Amor de Caridad" de Gerardo Diego}

Poesía galardonada con el primer premio y la Flor Natural en los Juegos Florales de Granada, celebrado con motivo del IV Centenario de la muerte de San Juan de Dios (1950). Al frente del poema aparece con una variante en el título: "Amor y Caridad". Lo transcribimos de la revista "Paz y Caridad", Número 4, julio-agosto, 1950, pp. 357-360. En la transcripción hemos respetado la división con asteriscos que aparecen entre las estrofas tal y como figuran en la revista. Observamos que existen también variantes gramaticales, de puntuación y de versificación con respecto al poema " $A$ San Juan de Dios" publicado en las obras completas de Gerardo Diego (Cf. tabla 2).

\section{“AMOR Y CARIDAD”}

Está el balcón abierto al sol de octubre.

El tibio, oblicuo halago

resbala su caricia

sobre el libro escolar como una mano.

La historia universal fulge y palpita

-oros y fuegos, Nínive y Bizancio-.

Sueña el niño y la hoja

-rebullicio de pájaros-

mueve el ala cautiva

alborotando brisas y relámpagos.

Ya las letras se enturbian. Ya los ojos miran, no ven la página. Ahondaron más allá de los siglos sus saetas y los siglos pueriles traspasaron.

El niño sueña ahora

en otro sol de octubre antiguo y raro, y besándole fiel la frente nueva, en otro niño sueña el sol acaso.

La Eternidad se ha hecho.

$Y$ el ayer y el mañana entresoñados están aquí en un puro, inmóvil éxtasis, alas abiertas del instante mágico.

$$
\text { * * * }
$$

Porque sí, es el hoy, es el ahora -botón florido, aun por abril, selladoel que vive el rapaz, tan pensativo, junto al balcón. Hay algo que lo comprueba, un hilo que dulcemente traba el vuelo al pájaro y lo retiene aqui en la jaula abierta, piando, aleteando.

$$
* \quad * \quad *
$$

Las ventanas de enfrente se han abierto y un cántico inunda de alegría 
la mañanera claridad del ámbito.

Blancas y azules voces cantan, cantan:

cuatro por una es cuatro,

cuatro por dos son ocho,

cuatro por tres son doce,

cuatro por cuatro, dieciséis.

$* \quad * \quad *$

$Y$ ahora es otro balcón y el sol de mayo tiende su escala de amarillo fuego

hasta el catre limpísimo

donde un anciano calla su secreto.

A abrevarse en las llagas

entran las moscas e invisible oxeo

abanica los átomos de oro

y entre el pus y el zumbido corre un velo.

Inmóvil, evadido de dolores

puede el yacente sumergirse en sueños

¿Qué es lo que ve, persigue,

fijo los ojos en la cal del techo?

* * *

El anciano contempla, se contempla

en la rompiente gloria del espejo.

Se mira como fue, mozo, gallardo,

niño tal vez, desamparado, angélico.

No, la vejez no existe,

las llagas no supuran. Y el atento

oído logra extraer del ritmo de la sangre

la inocente extensión ciega del tiempo.

Amor de hombre a mujer, de madre a hijo, amor mutuo y feliz, que se recrea, que abraza y vive en frutos de la carne, en destellos de dicha y de inocencia.

Amor, amor humano, yo lo canté y abril me vive y besa,

y en mi hogar bendecido

es siempre primavera.

$$
\text { * * * }
$$

Pero cuando el amor va de alma a alma por la línea más recta,

que es el Amor de Dios, y nada pide

y nada, nada espera,

es Caridad, amor de solo espíritu

que mueve ya otro sol y otras estrellas.
¿Cómo es la caridad? Nadie lo sabe.

Para saberlo es menester ser víctima, ser cordero de amor, ser y haber sido y haber de ser sustancia, esencia, prisma, Hombre y Dios, Padre, Hijo y Santo Espíritu.

Trinidad del Amor, una, infinita.

Nadie lo sabe aún. Mas lo sabremos, que ya el Pastor nos silva y nos abre los brazos

y a una más alta vida nos convida.

Lo iba aprendiendo, ahincando, lo estudiaba en el amor por Dios día tras día Juan de Dios y del prójimo; y ahora, granada ya su vida en la celeste acrópolis, lo sabe y lo comprueba de la misma Caridad, una y trina que se entrega; libro abierto, granada abierta y viva.

Saber la Caridad es la suprema, rica sabiduría.

De esa ciencia de amor ya deletrean Hijas, hermanos legos la cartilla y sobre enfermos, huérfanos, tullidos, gotea zumos la granada mística.

Gerardo Diego (De la Real Academia Española)

\section{FUENTES}

Revista "Paz y Caridad". Año 1950. 6 números. Números: 1 (enero-febrero); 2 (marzo-abril); 3 (mayojunio); 4 (julio-agosto); 5 (septiembre-octubre); 6 (noviembre-diciembre). Biblioteca Nacional de España. Signatura: Z/2528. Abreviaturas de cada número utilizadas en las citas internas del artículo: P y C 1(1950); P y C 2(1950); P y C 3(1950); P y C 4(1950); P y C 5(1950); P y C 6(1950).

\section{BIBLIOGRAFÍA}

- Abella, R. (1996): La vida cotidiana bajo el régimen de Franco. Madrid: Editorial Temas de Hoy.

- Alonso, D. (1979): Antología poética. Madrid: Alianza Editorial.

- Alonso de la Sierra, L. (2017): Artes suntuarios en el Cádiz Ilustrado. El Legado de Fray Agustín Pérez Valladolid. Sevilla: Fundación Cajasol Cádiz. 


\section{Cultura de los Cuidados}

- Álvarez Chillida, G. (1996): José María Pemán. Pensamiento y trayectoria de un monárquico (18971941). Cádiz: Servicio de Publicaciones de la Universidad de Cádiz.

- Arizmendi, M. (1986): “Introducción y bibliografía del autor". En Diego, G.: Manual de espumas. Versos Humanos (pp. 9-72). Madrid: Editorial Cátedra (Letras Hispánicas).

- Asenjo Sedano, J. (1988): Joan de Dios (Relato sobre la vida y la muerte del santo de los pobres de Granada). Granada: Editorial Don Quijote.

- Ayala, F. (1982): Recuerdos y olvidos. Madrid: Alianza Editorial.

- Ayala, F. (1993): El hechizado. San Juan de Dios. Madrid: Alianza Cien.

- Ayala, F. (2002): Los usurpadores. Edición de Carolyn Richmond. Madrid: Ediciones Cátedra.

- Barciela, C. (2000): “El mercado negro de productos agrarios en la posguerra, 1939-1953". En: Fontana, J. (ed.): España bajo el franquismo (pp. 192-205). Barcelona: Crítica.

- Bellido, J.F. (1995): El corazón de la Granada. Un santo llamado Juan de Dios. Editorial Desclée de Brouwer: Bilbao.

- Bengoechea, I. (1988): La felicidad en San Juan de la Cruz. Cádiz: Editorial Miriam.

- Bernal Salgado, J.L. (2011): "Prólogo". En Diego, G.: 100 poemas (pp. 9-20). Madrid: Ediciones de la Torre.

- Bernal Salgado, J.L. (2016): La poesía de Gerardo Diego (Estudio bibliográfico). Santander: Fundación Gerardo Diego.

- Blanco Aguinaga, C.; Rodríguez Puértolas; Zavala, I.M. (1984): Historia social de la Literatura española (en lengua castellana). III. Madrid: Castalia.

- Carrasco de Jaime, D.J. (2004): “San Juan de Dios: un tipo iconográfico peculiar en torno a la evolución pictórica de la imagen devota". Archivo Hospitalario, 2, 195-210.

- Carvajal, A. (s.f.e.): "Benítez Carrasco, Manuel". En: Diccionario de autores granadinos. Granada: Academia de Buenas Letras de Granada. Disponible

en

http://www.academiadebuenasletrasdegranada.or g/benitezcarrasco.pdf (Consultado el 6 de julio de 2018).

- Castro, F. de (facsímil 1995): Historia de la Vida y santas obras de San Juan de Dios y de la Institución de su Orden y principios de su Hospital. Edición facsímil. Córdoba.

- Catálogo filatélico (1977): Catálogo unificado y especializado de España y dependencias postales 1978. Madrid-Barcelona: Edifil, S. A.

- Cerro, J. del (2000): San Juan de Dios. Obra atribuida a Jacinto del Cerro. Sevilla: Hermanos de San Juan de Dios Curia Provincial Bética.

- Chouza-Calo, M.P. (2017): “Lope de Vega y el alma del pecador. Arrepentimiento y expiación en "Juan de Dios y Antón Martín". Disponible en http://edizionicafoscari.unive.it/media/pdf/books/ 978-88-6969-164-5/978-88-6969-164-5-ch-37.pdf

(Consultado el 7 de julio de 2018).

- Ciudad Gómez, J. (1963): Historia de la Orden Hospitalaria de S. Juan de Dios. Granada: Archivo Interprovincial Casa del Tránsito de San Juan de Dios.

- Clavijo y Clavijo, S. (1950a): Breve historia de la Orden Hospitalaria de San Juan de Dios en los ejércitos de mar y tierra. Trabajo premiado en el Certamen literario del IV Centenario de San Juan de Dios. Artes Gráficas Arges: Madrid.

- Clavijo y Clavijo, S. (1950b): La Orden Hospitalaria de San Juan de Dios en la Marina de Guerra de España. Presencia y nexo. Madrid.

- Cruset, J. (1964): San Juan de Dios. Una aventura iluminada. Barcelona: Editorial Aedos.

- Cruz, S. de la (1981): "Introducción”. En Otero, B.: Expresión y reunión. A modo de antología (pp. 9-48). Madrid: Alianza Editorial.

- Cruz Ayuso de la, C. (2016): "El amor social, condición necesaria para alcanzar el bien común". Revista de Fomento Social, 71, 103-106.

- Díaz Plaja, G. (1961): Historia de la Literatura Española encuadrada en la Universal. Barcelona: Ediciones La Espiga.

- Diego, G. (1967): "Ritmo y espíritu en Rubén Darío". Cuadernos Hispanoamericanos, 212-213, 247264.

- Diego, G. (1971): Versos divinos. Madrid: Fundación Conrado Blanco.

- Diego, G. (1974): Un jándalo en Cádiz. Madrid: Ediciones de la Caja de Ahorros de Cádiz.

- Diego, G. (1974): Poesía de creación. Barcelona: Seix Barral.

- Diego, G. (1986): Manual de Espumas. Versos Humanos. Edición de Milagros Arizmendi. Madrid: Editorial Cátedra (Letras Hispánicas).

- Diego, G. (1988): Antología poética. Santander: Instituto de Cultura de Cantabria.

- Diego, G. (1989): Obras completas. Poesías. Tomos I y II. Edición preparada por Gerardo Diego. Edición, introducción, cronología, bibliografía y notas de Francisco Javier Díez Revenga. Madrid: Aguilar.

- Diego, G. (1996): Obras completas. Poesías. 3 v. Edición preparada por Gerardo Diego. Edición, introducción, cronología, bibliografía y notas de Francisco Javier Díez Revenga. Madrid: Alfaguara.

- Diego, G. (2007): Poesía española (Antología). Edición de José Teruel. Madrid: Cátedra.

- Diego, G. (2011): 100 poemas. Prólogo y selección 
José Luis Bernal Salgado. Madrid: Ediciones de la Torre.

- Díez de Revenga, F.J. (s. f. e.): “Gerardo Diego y sus "Versos Divinos" (pp. 99-108). Disponible en: https://digitum.um.es/spui/bitstream/10201/21860/1 104\%20Gerardo\%20Diego\%20y\%20sus. $\% 20$ Versos $\%$ 20Divinos.pdf (Consultado el 10 de julio de 2018).

- Díez de Revenga, F.J. (1996): “Introducción". En Diego, G.: Obras completas. Poesías. Tomo I (pp. XIXXLIII). Madrid: Alfaguara.

- D'Isard, M. (1967): San Juan de Dios. Barcelona: Editorial Bruguera.

- Eslava Galán, J. (2010): Los años del miedo. La nueva España (1939-1952). Barcelona: Editorial Planeta.

- Eseverri Chaverri, C. (2001): Juan de Dios, el de Granada. Granada: Editorial La Vela.

- Felipe, L. (1981): Versos y oraciones de caminantes. Madrid: Visor.

- Felipe, L. (1984): Versos y blasfemias de caminantes. Madrid: Visor.

- Fernández Gaytán, J. (1983): “La Orden Hospitalaria de San Juan de Dios y la Real Armada". Revista General de Marina, 205, 323-337.

- Fernández Gaytán, J. (1984): “La Orden Hospitalaria de San Juan de Dios en los hospitales de la Real Armada". Revista General de Marina, 207, 237-250.

- Gallego Morell, A. (1972): "El ciprés de Silos en la poesía". En: Diez ensayos sobre literatura española (pp. 151-178). Madrid: Revista de Occidente.

- Gallego Morell, A. (2008): Vida y poesía de Gerardo Diego. Granada: Universidad de Granada y Fundación Gerardo Diego.

- Gaos, V.: (1975): Antología del grupo poético de 1927. Madrid: Cátedra.

- García Delgado, J.L. (2000): “Estancamiento industrial e intervencionismo económico durante el primer franquismo". En: Fontana, J. (ed.): España bajo el franquismo (pp. 170-191). Barcelona: Crítica.

- García Gil, J.M. (2018): Prender con keroseno el pasado. Una biografía de Carlos Edmundo de Ory. Sevilla: Fundación José Manuel Lara.

- García Hortelano, J. (1978): El grupo poético de los años 50 (Una antología). Madrid: Taurus Ediciones.

- García Martínez, A.C. et al. (1995): “Notas históricas sobre la vida de San Juan de Dios". Híades. Revista de Historia de la Enfermería, 2, 65-72.

- García Tejera, M.C. y Hernández Guerrero, J.A. (2003): Poetas andaluces de los años cincuenta. Estudio y antología. Barcelona: Fundación José Manuel Lara (Vandalia maior).

- Gila Medina, L. (2003): “Aproximación a la vida y obra del pintor y estofador alcalaíno-granadino Pedro Raxis". Archivo Español de Arte, LXXVI, 304, 389-406.
- Gómez-Moreno, M. (1950): San Juan de Dios. Primicias históricas suyas. Madrid: Provincias Españolas de la Orden Hospitalaria.

- Herrera-Rodríguez, F. (2005): La sanidad municipal en el Cádiz de la posguerra. Cádiz: Real Academia de Medicina y Cirugía de Cádiz.

- Hidalgo, A.M. (2015): "La educación rural en España en la década de 1950: la Unesco y los principios educativos del régimen franquista". Educaçao em Revista, 3, 119-142.

- Hierro, J. (1988): “Introducción". En Diego, G.: Antología poética (pp. 9-26). Santander: Instituto de Cultura de Cantabria.

- Hünermann, W. (1976): El mendigo de Granada. Semblanza de San Juan de Dios. Madrid: Studium ediciones.

- Hünermann, W. (1993): El mendigo de Granada. Vida de San Juan de Dios. Madrid: Ediciones Palabra.

- Javierre, J.M. (1996): Juan de Dios. Loco en Granada. Salamanca: Ediciones Sígueme.

- Juliá, S. (2008): “Edad Contemporánea”. En: Valdeón, J.; Pérez, J.; Juliá, S.: Historia de España (pp. 526-530). Madrid: Austral.

- Labrador, A. (1947): Vida del padre de los pobres. El Glorioso San Juan de Dios. Fundador de la Orden Hospitalaria y Patrón de los hospitales y enfermos. Madrid: Apostolado de la Prensa, S.A.

- Lacruz Alcocer, M. (1997): Entre surcos y pupitres: historia de la Educación Agraria en la España de Franco. Madrid: Endymion.

- López Martín, A.; Feito Pinela, U.; Martín Rodrigo, M. (2003): "Significado histórico de las revistas de la Orden Hospitalaria en España". Archivo Hospitalario, I, 161-176.

- Mainer, J.C. (2014): Historia mínima de la literatura española. Madrid: Turner Publicaciones S. L.

- Marín Ureña, J.M. (s. f. e.): “Gerardo Diego o el arte plural". Disponible en: file://C:/Users/USUARIO/Desktop/GERARDO\%2 0DIEGO\%200\%20EL\%20ARTE\%20PLURAL.pdf (Consultado el 10 de julio de 2018).

- Martínez Gil, J.L. (2000): "San Juan de Ávila, Director espiritual de San Juan de Dios". Salmanticensis, 47, 433-474.

- Martínez Gil, J.L. (2006): “Sobre el nacimiento y procedencia de San Juan de Dios y su obra". Hispania Sacra, Estudios de Edad Moderna, 58, 69-100.

- Molero Mesa, J. (1994): “Enfermedad y previsión social durante el primer franquismo (1936-1951). El frustrado seguro obligatorio contra la tuberculosis". Dynamis, 14, 199-225.

- Montoya, J.L. (1996): “El nuevo libro del poeta Manuel Benítez Carrasco, «Aires de Andalucía», se presentará hoy en Sevilla". ABC: 17-XII, p. 107.

- Ordine ospedaliero di S. Giovanni di Dio Curia 


\section{Cultura de los Cuidados}

Generalizia (s. f. e.): Giovanni di Dio (nelle opere di Onofrio Bramante). Roma: Curia Generalizia dei Fatebenefratelli.

- Otero, B. de (1981): Expresión y reunión. A modo de antología. Madrid: Alianza Editorial.

- Otero, H. (2016): "El Viacrucis del «católico poeta» Gerardo Diego. En Otero, H. (ed.): El viacrucis de Gerardo Diego (pp. 3-15). Madrid: PPC editorial.

- Pemán, J. Ma. (2006): “«El jándalo» al vuelo. En: Pemán, J. Mà.: Siluetas literarias (pp. 143-146). Antología de Juan Lamillar. Madrid: Caja San Fernando.

- Puente, A. y Salcines, L.A. (2012): Diccionario bibliográfico de la poesía en Cantabria (1970-2010). Santander: Fundación Gerardo Diego.

- Ramos Santana, A. (1999): Cultura y política en la España de Franco. Una historia de los Cursos de Verano de Cádiz (1950-1981). Cádiz: Servicio de Publicaciones. Vicerrectorado de Extensión Universitaria (Universidad de Cádiz).

- Richmond, C. (2002): "Introducción". En Ayala, F.: Los usurpadores (pp. 13-85). Madrid: Ediciones Cátedra.

- Romero López, F. (2010): Leyendas y tradiciones zamoranas. Zamora: Imprenta Jambrina.

- Rondón, J. M․ (2016): “Las tres fotografías de la Generación del 27". Diario de Sevilla, 18-XII. Disponible en

https://www.diariodesevilla.es/ocio/fotografias-

Generacion 01091591245 (Consultado el 12 de julio de 2018).

- Rubio Martín, T. (2014): La obra religiosa de Gerardo Diego (Verso y prosa). Quito: Universidad Politécnica Salesiana.

- Ruiz Ortega, E. (1983): La Granada de San Juan de Dios. Guía artística del peregrino. Imprenta Copartgraf, s. c.: Granada.

- San Juan de Dios (2006): Cartas. Edición preparada por J.I. Fernández de Viana y otros. Madrid:
Fundación Juan Ciudad. Orden Hospitalaria de San Juan de Dios.

- Silver, P.W. (1979): "Dámaso Alonso, presentación mínima". En Alonso, D.: Antología poética (pp. 7-22). Madrid: Alianza Editorial.

- Tamames, R. (1985): Una idea de España. Ayer, hoy y mañana. Barcelona: Plaza \& Janes, S.A.

- Teruel, J. (2007): “Introducción”. En Diego, G.: Poesía española (Antologías) (pp. 11-86). Edición de José Teruel. Madrid: Cátedra.

- Trapiello, A. (2010): Las armas y las letras. Literatura y guerra civil (1936-1939). Barcelona: Destino.

- Trueba, F. (1978): “El hombre que supo amar: una superproducción penosa". El País: 1-IX. Disponible en

https://elpais.com/diario/1978/09/01/cultura/2734488 05 850215.html (consultado el 7 de julio de 2018).

- Tusell, J. y Álvarez Chillida, G. (1998): Pemán. Un trayecto intelectual desde la extrema derecha hasta la democracia. Barcelona: Editorial Planeta.

- Umbral, F. (1978): La noche que llegué al Café Gijón. 2.․․ edición. Barcelona: Ediciones Destino.

- Umbral, F. (1994): “El piano alegre de Gerardo Diego". En Umbral, F.: Las palabras de la tribu (De Rubén Darío a Cela). Barcelona: Editorial Planeta.

- Valls, R. (2000): “Ideología franquista y enseñanza de la Historia en España, 1938-1953". En: Fontana, J. (ed.): España bajo el franquismo (pp. 230-245). Barcelona: Crítica.

- Vázquez Montalbán, M. (1986): Crónica sentimental de España. Madrid: Espasa Calpe.

- Ventosa Esquinaldo, F. (2012): Pensamiento de San Juan de Dios y la Orden hospitalaria y su relación con la enfermería: conceptos y valores. Granada: Colección Temas Históricos O.H. Archivo Museo de San Juan de Dios "Casa de los Pisas".

- Vidal Ortuño, J.M. (2013): “La Virgen María en la obra de Gerardo Diego". Razón y fe, 1381, 385-395. 